\title{
Viral hepatitis B and C. Cure or treatment?
}

\author{
Dimitrios A. Kountouras \\ “Mitera" Hospital, Athens, Greece
}

\begin{abstract}
$\mathrm{HBV}$ and HCV infections are among the most important global health problems; both represent also the leading cause of cirrhosis and HCC worldwide. HBV treatment cannot be considered cure but effective viral suppression can be achieved and remains the current principal goal of therapy. Talking about HCV treatment today equals to talking about total cure of the patient, with treatments of very high SVR rates, shorter if not shortest duration, minimal risk for resistance, pangenotypic and practically with no serious adverse events, no fibrosis or previous treatment status limitations, but also with a very high cost.
\end{abstract}

\section{Chronic HBV infection}

$\mathrm{HBV}$ infection remains one of the most important global health problems as $\mathrm{HBV}$ is $50-100$ times more infectious than HIV, so that 2 billion people worldwide have been infected with $\mathrm{HBV}^{1}$ and about 350 millions of them are chronic carriers. As a result, HBV represents the leading cause of cirrhosis and HCC worldwide. ${ }^{2}$ Almost $80 \%$ of all HCC in Asian Americans is attributed to $\mathrm{HBV} .^{3}$ Hepatocellular carcinoma is second only to tobacco in causing the most cancer deaths ${ }^{4}$ and unfortunately, $30 \%$ to $50 \%$ of HCC has been associated with HBV in the absence of cirrhosis. ${ }^{5}$

Following the global prevalence data it is important to notice that high prevalence areas are located in poor or under developed regions of the world, implicating that poor socioeconomic resources and lack of health services network will play a critical role in any future campaigns to eliminate the disease (Figure 1).

Under this huge, global burden of the disease, the approaches to face the disease are prevention through complete vaccination, proper surveillance and reliable diagnosis and therapy, in the end. According to that, early vaccination programs seem to be the only reasonable,

Correspondence: Dimitrios A. Kountouras, "Mitera" Hospital, Athens, Greece E-mail: kuduras@hol.gr

Key words: HBV infection; viral hepatitis B; viral hepatitis C; transmission; worldwide.

(c) Copyright D.A. Kountouras, 2014

Licensee PAGEPress, Italy

Thalassemia Reports 2014; 4:4870

doi:10.4081/thal.2014.4870

This article is distributed under the terms of the Creative Commons Attribution Noncommercial License (by-nc 3.0) which permits any noncommercial use, distribution, and reproduction in any medium, provided the original author(s) and source are credited. safe and totally effective choice for the best cost-benefit outcomes, before any diagnosis and treatment strategies give fruit. The additional reason is that, public awareness and medical surveillance are still far from the point to be considered adequate. Even in the US, It is estimated that about $2,000,000$ people have chronic HBV, only $400-600.000$ are diagnosed and 200-300,000 entered into care, while less than 50,000 are receiving antiviral treatment .

The pattern of transmission and outcome towards chronic disease of $\mathrm{HBV}$ infection in young age is the most important point for the prevention of the disease (Figure 2). Almost $90 \%$ of infants infected progress to chronic disease, ${ }^{6}$ thus implicating that early vaccination remains the gold standard in the prospect of elimination of the disease. Universal vaccination of infants recommended in 1991 the US achived an $80 \%$ decline in incidence of new $\mathrm{HBV}$ infections (Figure 3 ). ${ }^{7}$

HBV nationwide vaccination implemented on July 1984 in the Taiwanese population, proved also effective in reducing HCC incidence and mortality in the following years (Figure 4$).{ }^{8}$

The progression of chronic HBV results in 30\% to cirrhosis with $25 \%$ progression to decompensation and liver failure within 5 years of developing cirrhosis (Figure 5).${ }^{9}$ Independently of developing cirrhosis or not $30 \%$ of chronically infected individuals will present with HCC. ${ }^{10}$ In the end, a large percentage of patients will need to be transplanted, making chronic HBV the $6^{\text {th }}$ leading cause of liver transplantation in US. ${ }^{11}$

Discussing treatment modalities and probability for cure it is important to bear in mind the different types of patients with chronic HBV, in order to define the treatment targets. The two major distinctions are the HBeAg (+), meaning the high viral replication and activity and the HBeAg (-) patients. The HBeAg (-) patients either follow the pattern of the inactive carrier state or the reactivation HBeAg-negative chronic hepatitis, with chronic inflammation and progression to cirrhosis (Figure 6).

After spontaneous HBeAg seroconversion, 67 to $80 \%$ of inactive carriers (and not really healthy carriers) remain in inactive carrier state, $4-20 \%$ of them revert back to $\mathrm{HBeAg}$ positivity and $10-20 \%$ of them have reactivation after years. ${ }^{12}$ Thiw means that HBeAg- Negative Chronic HBV have moderate, often fluctuating levels of serum HBV DNA and elevated transaminases, often fluctuating too. ${ }^{13}$

HBV cure equals to HBsAg seroconversion. Nevertheless, during the last years it has been clearly demonstrated that HBV viral load represents the most important factor determining the fate of the liver. This has been the conclusion of several studies, most notably the REVEAL trial. In this prospective, multicenter, observational cohort study performed in Taiwan, assessment of the incidence of both cirrhosis and HCC in HBsAg-positive patients proved that over 13 years of follow-up, patients with baseline HBV DNA levels $<300$ copies/mL, had a $5 \%$ likelihood of developing liver cirrhosis, while as baseline HBV DNA levels increased, the incidence of liver cirrhosis over time steadily increased such that almost $40 \%$ of individuals with baseline HBV DNA levels $\geq 1.0$ $x 10^{\wedge} 6$ copies/mL developed liver cirrhosis in the end of the follow up (Figures 7 and 8 ). ${ }^{14}$ This was independent of the the HBeAg status.

The same time cumulative incidence of HCC over 13 years was much higher among patients who had very high baseline HBV DNA levels compared with those who had lower baseline HBV DNA levels 
and the relationship between HBV DNA level at baseline and HCC risk persisted regardless of HBeAg status or ALT levels. Therefore, baseline HBV DNA level represents an independent risk factor for the development of liver cirrhosis and HCC (Figure 9). ${ }^{15}$

Morover, in the same study clearance of HBV DNA, not HBeAg or HBsAg, reduced the risk of HCC and HBV DNA suppression independently associated with significantly reduced risk of HCC. Greatest reduction in HCC incidence observed among pts with high baseline HBV DNA ( $\geq 100,000$ copies/mL) who cleared HBV DNA during follow-up. HCC incidence was highest in pts HBeAg seropositive throughout follow-up and most interestingly, HBsAg suppression was not associated with reduced incidence of HCC .

Approved treatments for HBV infection are Interferon, either standard or Pegylated, with both antiviral and immunomodulatory activity and either nucleotide or nucleoside analogs, Lamivudine, Adefovir, Entecavir, Tenofovir and Telbivune. Rates of response and resistance to these medications are summarized in Table $1 .^{16}$

IFN may lead to a higher rate of HBeAg and HBsAg loss and more durable viral suppression. 48 weeks treatment with pegylated-interferon (PEG-IFN) in HBeAg-positive patients resulted in $29 \%$ to $32 \% \mathrm{HBeAg}$ seroconversion and $3 \%$ to $7 \%$ HBsAg loss 24 weeks after completion of treatment. ${ }^{17,18}$

Follow-up evaluation of patients for 3.5 years after completion of treatment found that HBeAg loss was durable in $81 \%$ and HBsAg loss occurred in 30\% (58\% for genotype A and 11\% for genotype non-A) of patients. ${ }^{19}$ Phase 3 clinical trials showed that 1 -year treatment of PEGIFN with or without lamivudine in HBeAg-negative patients resulted in a sustained response, defined as normalization of ALT level, suppression of HBV DNA levels to $10,000 \mathrm{IU} / \mathrm{mL}$ or less in approximately $25 \%$ of patients and HBsAg loss in $9 \%$ at 3 years after completion of treatment. ${ }^{20}$ Major drawbacks of this treatment remain the side effects like flu-like symptoms and strong advantages the definite duration of treatment, the lack of resistance development to treatment and relatively high rate of HBs seroconversion, not expected with NUCs. ${ }^{21,22}$

Nucleos(t)ide Analogues (NUCs), that inhibit the viral polymerase, are the main treatment options for CHBV today. ${ }^{23-35}$ They are administered orally, presenting potent antiviral activity and few and very rare side effects (mitochondrial toxicity and lactic acidosis in patients with decompensated liver function treated with entecavir, ${ }^{26}$ myopathy and neuropathy in patients treated with telbivudine, ${ }^{27}$ and nephrotoxicity and renal tubular dysfunction in patients receiving adefovir or tenofovir). ${ }^{28}$

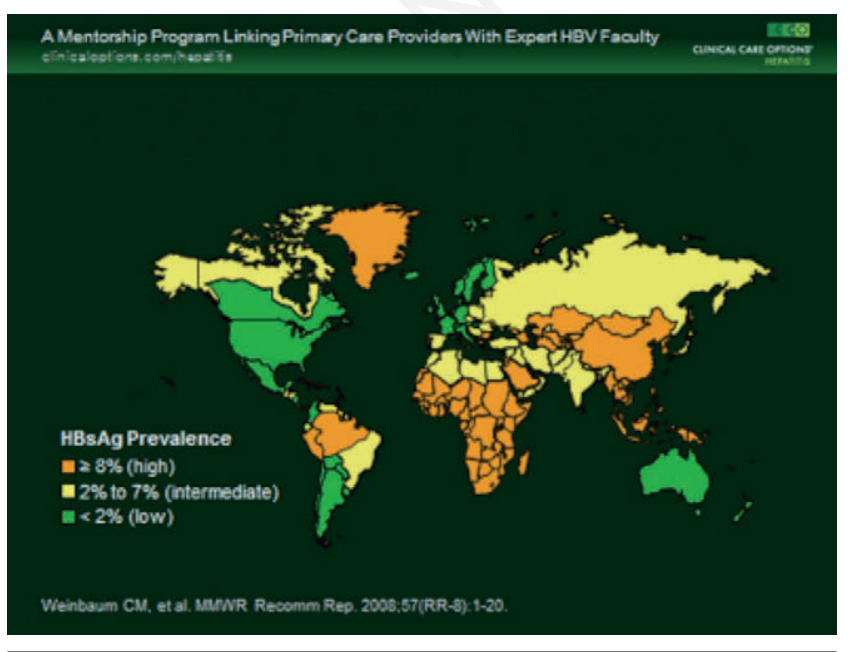

Figure 1. Screen for HBV in individuals born in intermediate/high prevalence locations.
High rate of drug resistance or low potency and slow response to treatment have been the weak points of the first and second generation of NUCs (Lamivudine, Adefovir). Both, older or new, cannot be stopped without the risk of recurrence of viremia and they are mainly used as treatments of indefinite duration. New drugs like entecavir and tenofovir, have high barriers to resistance, with very low rates of drug resistance after 5 years of treatment ( $1.2 \%$ and $0 \%$, respectively) ${ }^{29,30}$ The risk of entecavir resistance is much higher, $51 \%$ after 5 years of treatment, in patients with lamivudine-resistant HBV. ${ }^{31}$ Continued treatment with entecavir or tenofovir for up to 5 years resulted in undetectable serum HBV DNA levels in $94 \%$ to $98 \%$ of patients, HBeAg seroconversion in $40 \%$ to $41 \%$ of HBeAg-positive patients, and HBsAg loss in $3 \%$ to $10 \%$, while long-term viral suppression has been shown to reverse fibrosis and cirrhosis. ${ }^{24,32}$

HBV treatment cannot be considered cure yet. In the era of NUCs, treatment is effective in achieving the current principal goal of therapy that is fast, potent and sustained viral suppression, and secondary HBeAg seroconversion or HBsAg seroconversion that still remains the ultimate task. ${ }^{33}$ It is also important to realize that even HBsAg serocon-

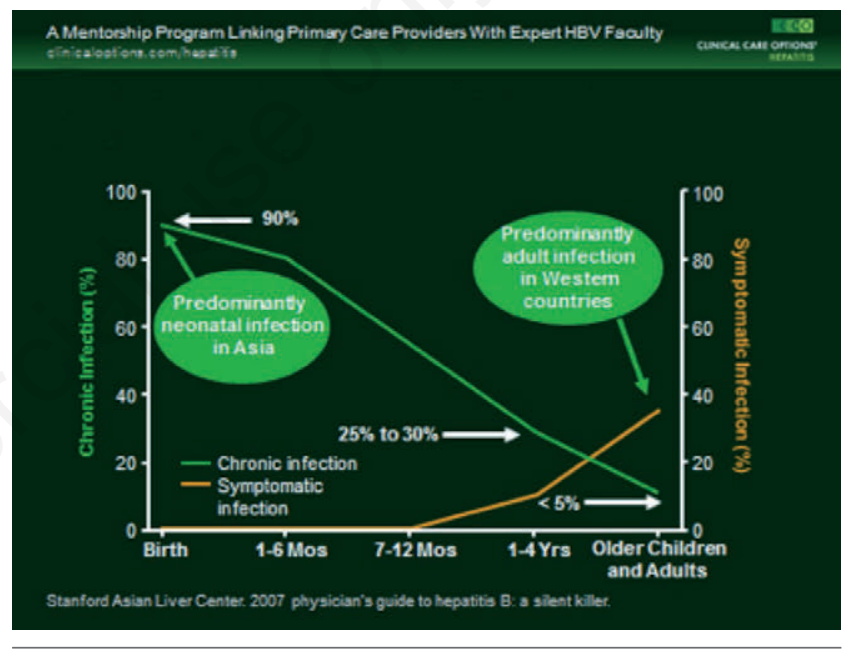

Figure 2. Outcome of HBV infection by age of transmission.

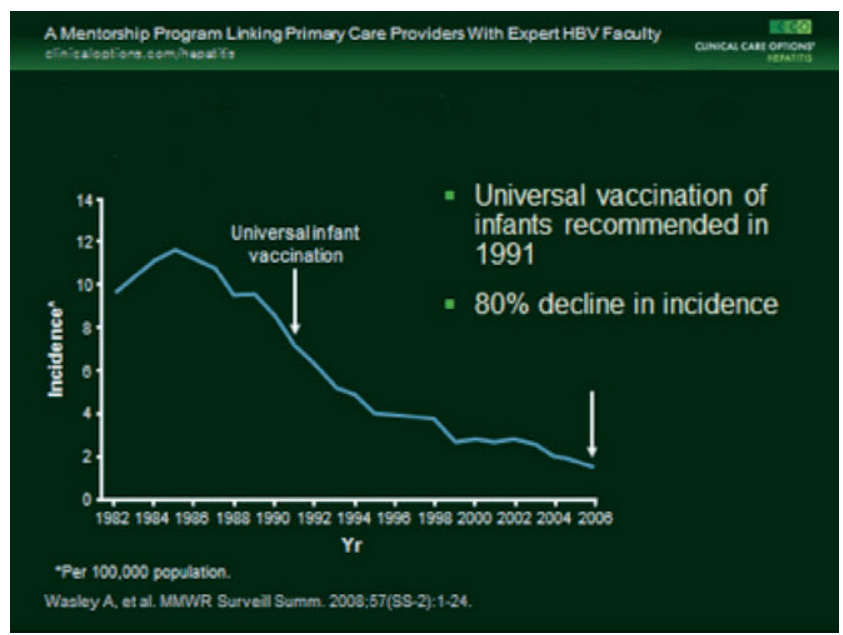

Figure 3. Acute HBV infection incidence in the US (1982-2006). 
A Mentorship Program Linking Primary Care Providers With Expert HBV Facult

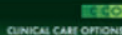

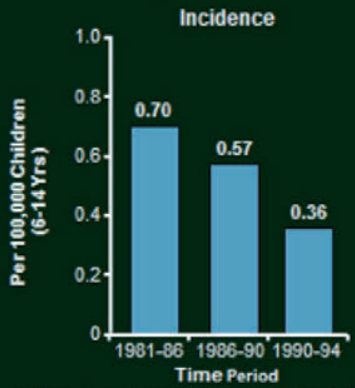

"Nationwide vaccination in Takran, implemented July 1984

Chang MH, et al. N Engl J Med. 1997:338:1855-1859.

Figure 4. Effect of HBV vaccination on HCC incidence and mortality.

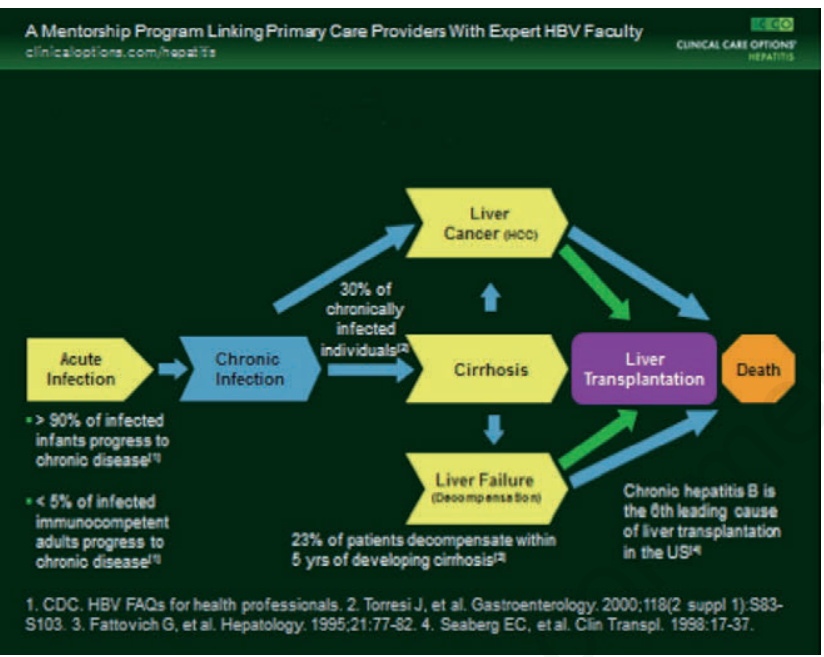

Figure 5. Hepatitis B disease progression.

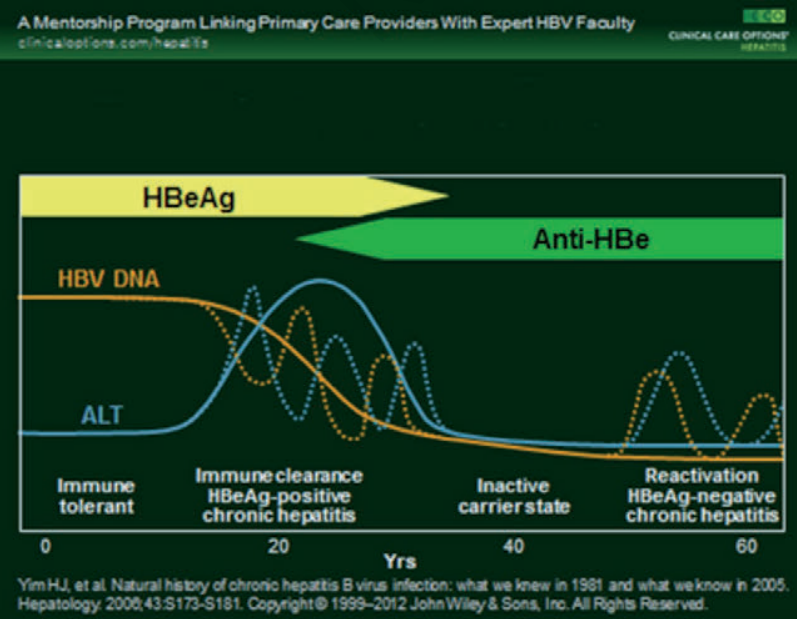

Figure 6. Phases of chronic HBV infection.
A Mentorship Program Linking Primary Care Providers With Expert HeV Faculty

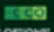

Aicalootions co-rineoz:t:

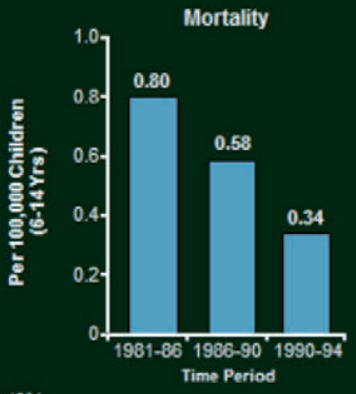

libeje UH, et al. Gastroenterology. 2000, $130.078-600$

$\mathrm{N}=3582$ Taiwanese patients

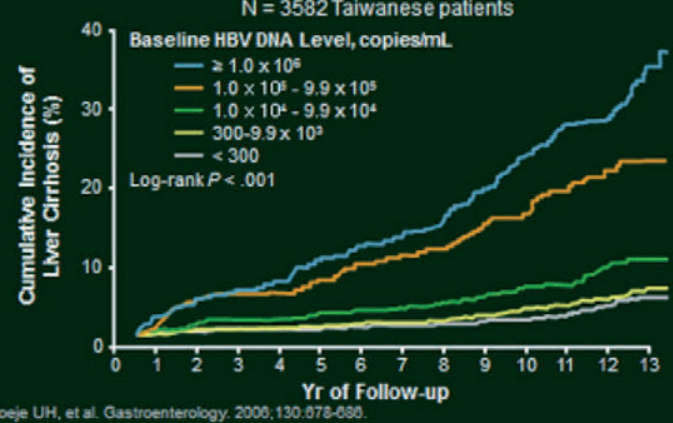

Figure 7. Cumulative incidence of cirrhosis by serum HBV DNA level at study entry.
Figure 8. REVEAL: Relationship between baseline HBV DNA and cirrhosis.

A Mentorship Program Linking Primary Care Providers With Expert HBV Facults
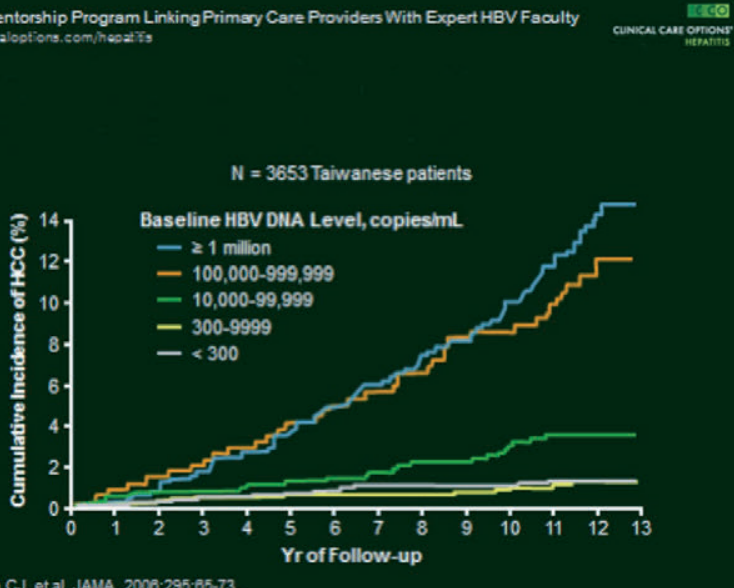

Chen CJ, et al. JAMA. 2006;295;05-73.

Figure 9. Cumulative incidence of HCC by serum HBV DNA level at study entry. 
version does not eliminate the risk for developing HCC. The risk for the recurrence of the infection ${ }^{34}$ and HCC has been associated with the remaining covalently closed circular DNA (cccDNA), that is not eradicated with current treatments. ${ }^{35}$ The latter is the source of renewed viral replication in case of immune depression or after antiviral drug withdrawal. ${ }^{36-39}$

The effort to reach HBV cure will be long but it has already been safer, efficient in preventing liver cirrhosis and decompensation and lowering the incidence of HCC in treated patients. Universal and early vaccination of infants remains the best approach, hoping that one day HBV could be only history for the humanity.

\section{Chronic HCV infection}

HCV infection is a global disease and the real incidence is not well known, because acute infection is generally asymptomatic ${ }^{40}$. WHO estimates that about $3 \%$ of the world's population has been infected with HCV and that there are more than 170 million chronic carriers who are at risk of developing liver cirrhosis and/or liver cancer.

In the United States 2 to 4 million persons are infected whereas in Europe the numbers are 5 to 10 million and about 12 million in India. Most European countries report a prevalence of HCV in the general

Table 1. Response rates and genotypic resistance rates to approved therapies in $\mathrm{HBeAg}$-positive and $\mathrm{HBeAg}$-negative patients.

\begin{tabular}{|c|c|c|c|c|c|c|c|}
\hline \multirow{2}{*}{$\begin{array}{l}\text { Treatment response } \\
\text { parameters }\end{array}$} & \multicolumn{7}{|c|}{ Approved therapies } \\
\hline & Lamivudine & $\begin{array}{l}\text { Adefovir } \\
\text { dipivoxil }\end{array}$ & Entecavir & Telbivudine & $\begin{array}{l}\text { Tenofovir } \\
\text { disoproxil } \\
\text { fumarate }\end{array}$ & PEG-IFNa & $\begin{array}{l}\text { PEG-IFN plus } \\
\text { lamivudine }^{\mathrm{a}}\end{array}$ \\
\hline
\end{tabular}

HBeAg-positive patients

At week 48 or 52

HBeAg seroconversion, \%

HBsAg loss, $\%$

Histologic improvement, $\%{ }^{\mathrm{b}}$

Genotypic resistance, $\%$

$\begin{array}{cc}36-44 & 13-21 \\ 16-21 & 12-18 \\ <1 & 0 \\ 49-56 & 53 \\ 27 & 0\end{array}$

$\begin{array}{cc}67 & 60 \\ 21 & 22 \\ 2 & 0 \\ 72 & 65 \\ 0 & 4.4\end{array}$

$\begin{array}{ccc}76 & 25 & 69 \\ 21 & 27 & 24 \\ 3 & 3 & 3-7 \\ 74 & 38 & 41 \\ 0 & 0 & 4-11\end{array}$

During extended treatment ${ }^{\mathrm{c}}$ Undetectable HBV DNA level

HBeAg seroconversion

HBsAg loss

39 (2)

$47(3)$

39 (5)

$0-3(2-3)$

48 (5)

2 (5)

Genotypic resistance

65 (5)

$42(5)$

94 (5)

$41(5)$

5 (2)

HBeAg-negative patients

At week 48 or 52

Undetectable HBV DNA level, \%

HBsAg loss, \%

Histologic improvement, $\%{ }^{\mathrm{b}}$

Genotypic resistance, \%

During extended treatment ${ }^{\mathrm{c}}$

Undetectable HBV DNA level, \%

HBsAg loss, \%

Genotypic resistance, \%

$60-73$
$<1$
$60-66$
23

$\begin{array}{cc}51 & 9 \\ 0 & < \\ 64-69 & 70 \\ 0 & 0.2\end{array}$

$\begin{array}{ll}90 & 88 \\ <1 & <1 \\ 70 & 67 \\ 0.2 & 2.7\end{array}$

$79(4)$
$42(4)$
$1.3(2)$
$21(2)$

97 (5)

40 (5)

$10(5)$

0 (5)

$\begin{array}{lc}19(3.5)^{\mathrm{c}} & 26(3.0)^{\mathrm{c}} \\ 37(3.5)^{\mathrm{c}} & 25(3.0)^{\mathrm{c}} \\ 11(3.5)^{\mathrm{c}} & 15(3.0)^{\mathrm{c}} \\ 0 & \mathrm{NA}\end{array}$

69 24 -7 41 4-11

Genotypic resistance, $\% \quad 70-80(5) \quad 29(5)$

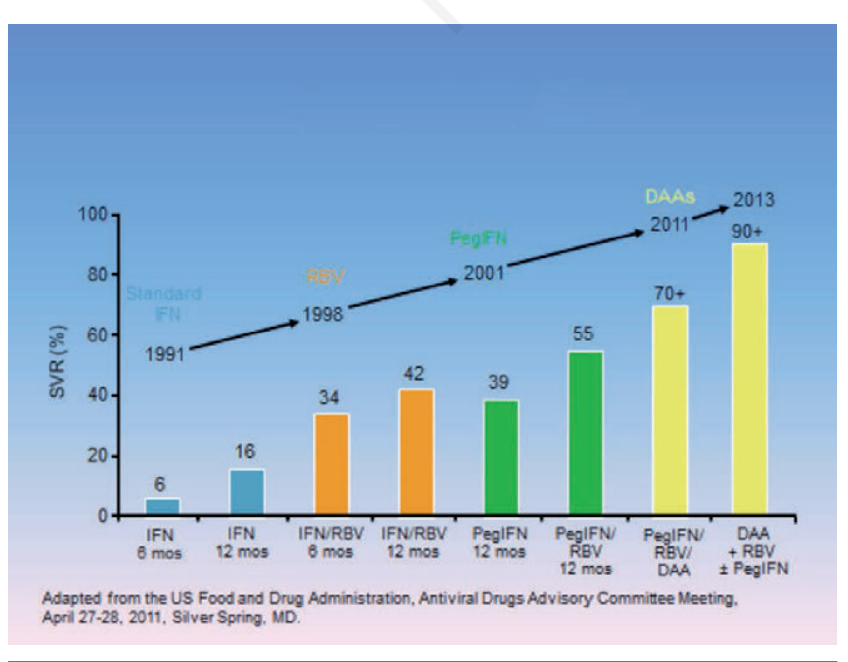

Figure 10. The good news.

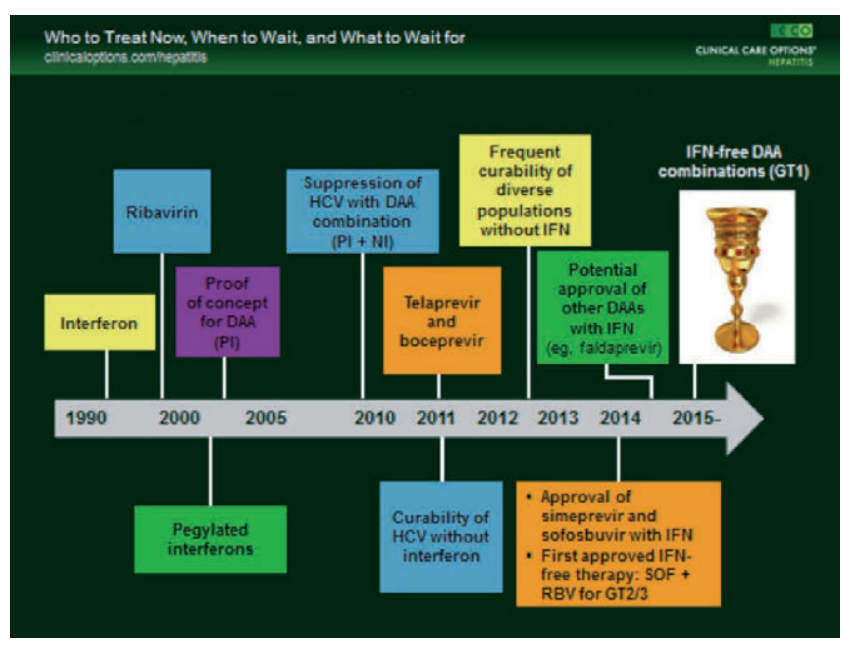

Figure 11. HCV therapy: past, present and future. 
population of between 0.5 and $2 \%$. Until 1990/1991 when anti-HCV screening tests for blood donors were introduced in Europe and the United States, HCV represented the major cause of transfusion-associated hepatitis. About 150,000 new cases occur annually in the US and in Western Europe, and about 350,000 in Japan. Of these, about $25 \%$ are symptomatic, but 60 to $80 \%$ may progress to chronic liver disease, and $20 \%$ of these develop cirrhosis.

Very high rates of HCV antibody reactivity ( $>70 \%$ ) have been reported in injecting drug users and in haemophiliacs. Intermediate prevalences of 20 to $30 \%$ have been observed in patients receiving haemodialysis. The incidence is declining since transmission by blood products has been reduced to almost zero and universal precautions in medical settings are followed.

The course of the disease is asymptomatic in most patients with or without ALT abnormalities and with or without chronic inflammation and increasing fibrosis in the liver. HCV infection may resolve without any clinical signs of liver disease in individuals exposed to low dose inoculum and that these cases may develop T cell immunity even in the absence of anti-HCV seroconversion. Rates of complete biochemical and virological resolution of acute hepatitis $C$ range between 10 and 50\%, and are probably affected by the route of infection, size and type of inoculum and acute phase clinical features. In chronic hepatitis $\mathrm{C}$, fibrosis progression is extremely variable over time and can be partially predicted by the age at infection, disease duration, liver histologic activity and stage of fibrosis and by the ALT profile. In patients who have developed cirrhosis, the 5-year risk of decompensation is between 15 and $20 \%$ and that of hepatocellular carcinoma around $10 \%{ }^{40}$

Most new infections are the consequence of high risk drug behavior (60\%) or unsafe injection practices.

There is no vaccine available yet because of the genetic diversity of HCV (RNA virus, high replication with a lot of genotypes and subtypes). There is also no effective post-exposure prophylaxis (immune globulin, antiviral agents) because passive immune prophylaxis against HCV using immune globulin containing detectable levels of anti-HCV has not been convincingly documented.

The fact that HCV was discovered lately in the end of $80 \mathrm{~s}$ makes it look like a new disease and it really is taking into consideration the rapid progress of HCV therapy over the last number of years, as there has been really a dramatic change in the treatment landscape. Talking about HCV treatment we can talk about cure because we are going from cure rates of under $10 \%$ with standard interferon through expectations of over $90 \%$ treatment efficacy now, with the most recently approved direct-acting antivirals in combination with peginterferon and ribavirin or even better with interferon free combinations of DAAs (Direct acting antivirals).

In about 1991 interferon was the first treatment approved for hepatitis C, 3 million units three times weekly, with moderate to poor results, particularly in genotype 1 patients. In 1998 IFN+ribavirin combination emerged as a significant promising evolution in the treatment of HCV that proved better than INF alone and that was going to be useful until today as additional drug to certain schemes including PegIFN or even DAA. PegIFNs have been a major advance in the route of progression offering single weekly dosing and really superior SVR results.

In 2002, the first proof of concept was presented for the ability to suppress HCV replication, specifically in genotype 1, with the first protease inhibitor called BILN-2061, that was halted because of cardiotoxicity in a monkey model. ${ }^{41}$ In 2009 , the combination of a protease inhibitor called danoprevir and a nucleotide polymerase inhibitor called mericitabine showing the capacity to suppress HCV replication. ${ }^{42}$

In 2011, the introduction of the 2 protease inhibitors, telaprevir and boceprevir, were presented after completed phase III trials, raising expectations for the new drug category and considerations for the SAEs the same time.

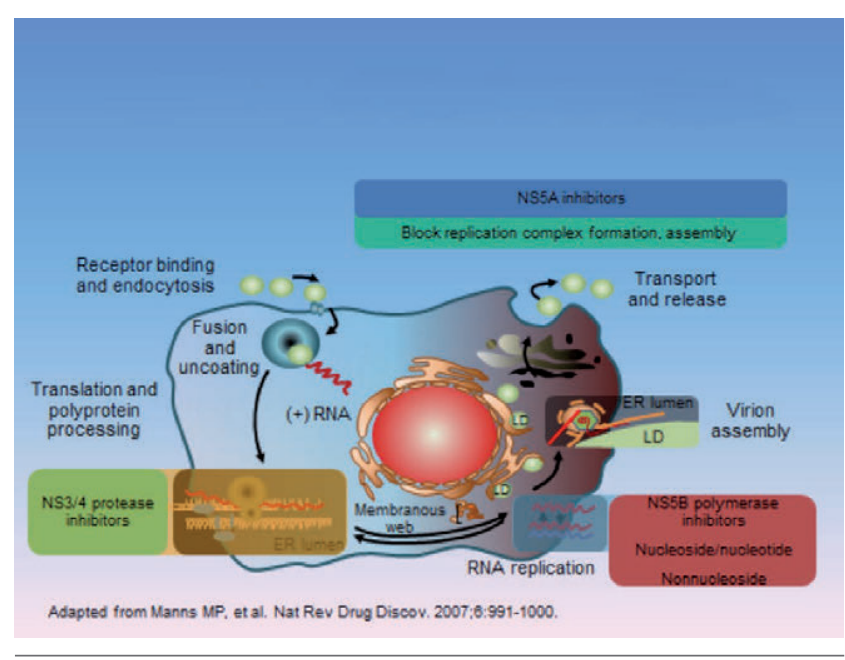

Figure 12. HCV life cycle and DAA target.

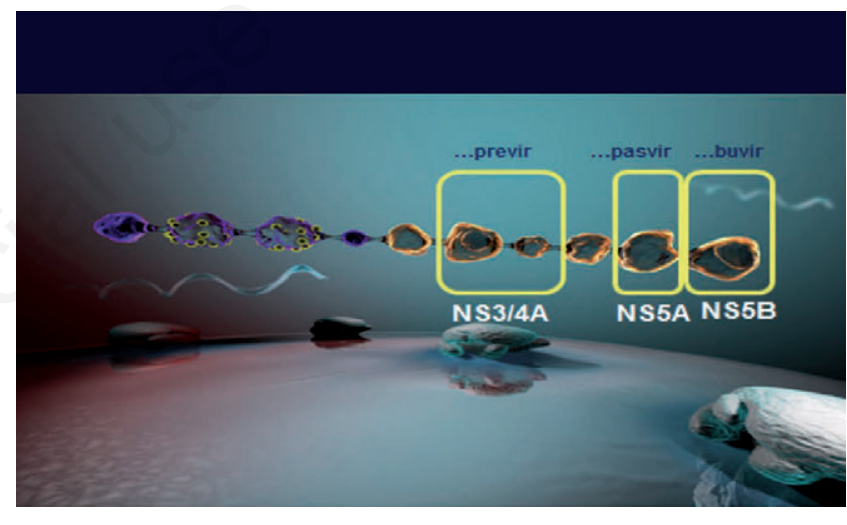

Figure 13. DAAs.

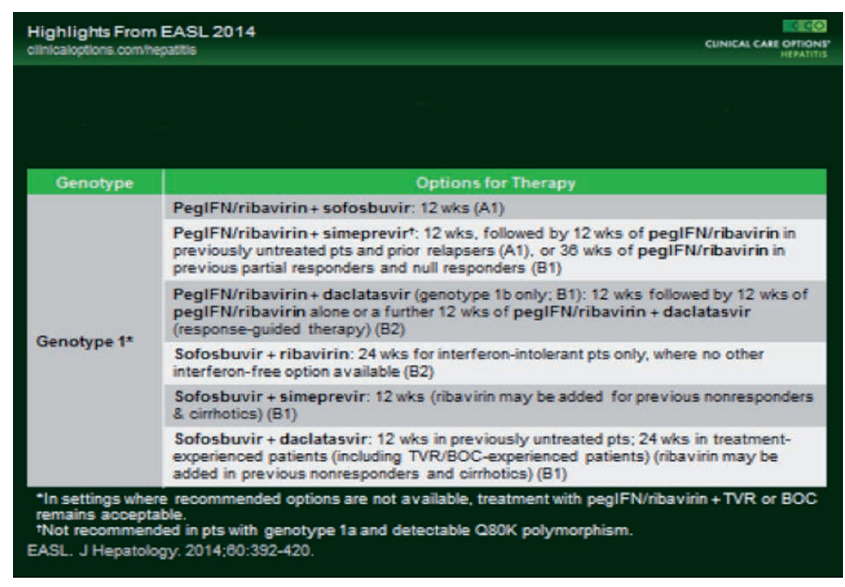

Figure 14. EASL HCV guidelines 2014: Genotype 1. 
In the following years the streaming development of new DAA therapies particularly the IFN free regimens and their combinations, established the confidence about the near future and the curability of HCV without interferon and indifferently of genotype, previous treatment or fibrosis status (Figure 10).

Unlike HBV, HCV virus presents multiple functional sites for drug interventions and plenty of potential targets for drug development. As a result, multiple classes of direct-acting antivirals have been developed targeting different points of the HCV life cycle (Figure 11). Translation of the viral RNA to the viral poly-protein after entering the cell and then the protease activation for separating the different functional parts that are commited to the viral RNA replication and assembly.

The first direct-acting antivirals were inhibitors of the NS3/4A protease. The second target for inhibition has been HCV NS5B polymerase, with both nucleotide polymerase inhibitors and nonnucleotide or nonnucleoside polymerase inhibitors, which act by a different mechanism of action but target the same enzyme. The third target has been the procedure of assembly through part of the replication complex involved in assembly, the nonstructural 5A protein-or NS5A. A number of direct-acting antivirals target the NS5A protein. So far the DAAs fleet that has gone through clinical development includes protease inhibitors, nucleotide and nonnucleotide polymerase inhibitors, and NS5A inhibitors (Figures 12 and 13). ${ }^{43}$

First generation protease inhibitors conferred a very good SVR rate in prior relapsers, in fact, better than naive patients, while in prior null responders, unfortunately the addition of one of boceprevir or telaprevir still led to suboptimal SVR rates, in the range of only $30 \%$ to $40 \%$, along with the risk of common AEs of this class of drugs. ${ }^{44,45}$

The results of multiple studies for the new agents and their combinations conducted during these years culminated in the current guidelines for the treatment of HCV for all genotypes. ${ }^{46}$ Current treatments are highly effective, with SVR rates miraculously of above $90 \%$, independently of the previous treatment status of the patients, the genotype, the viral load or the fibrosis status. ${ }^{47}$ Nevertheless the duration of treatment varies between 12 to 24 weeks, in respect of the previous treatment response, the presence of cirrhosis and the $\mathrm{Q} 80 \mathrm{~K}$ polymorphism for the genotype $1 a^{48}$ Shorter treatment options are on the way although. ${ }^{49}$

Cirrhosis, is no longer the negative prognostic factor limiting the SVR rates, especially in difficult to treat genotypes like Genotype 1 (Figure 14) ${ }^{50}$ while transplant recipients can be easily and effectively treated with excellent SVR results. ${ }^{51}$

The future treatments are heading towards IFN free regimens for both naïve or experienced patients. ${ }^{52,53}$ The trends are using an NS5B polymerase inhibitor in combination with an NS3/4 protease inhibitor and/or an NS5A inhibitor, in a carefully personalized concept. ${ }^{54-56}$ Even patients previously not eligible for treatment due to contraindicatios or decompensation can be effectively cured. ${ }^{57}$ The current data are predicting a triple combination as an optimal choice for maximum effectiveness and shorter duration of treatment. ${ }^{58,59}$ Surprisingly, Genotype 3 seems to be the new difficult to treat genotype in patients with severe fibrosis and probably older infection (Figure 15). ${ }^{60,61}$

The data about resistance issues are very encouraging so far, as viral fitness after resistance emergence is not clinically important and combinations of different types of drugs can achieve elimination of the incidence of resistance. Baseline protease inhibitor resistance is rare, with the exception of $\mathrm{Q} 80 \mathrm{~K}$, emergence of resistance is common in patients who do not achieve an SVR, resistance pathways are dependent on drug exposure and viral genotype, potency and genetic barrier of regimen play major roles in inhibiting resistance and finally resistant populations tend to be replaced by wild-type virus over time (Figure 16)..$^{62-64}$

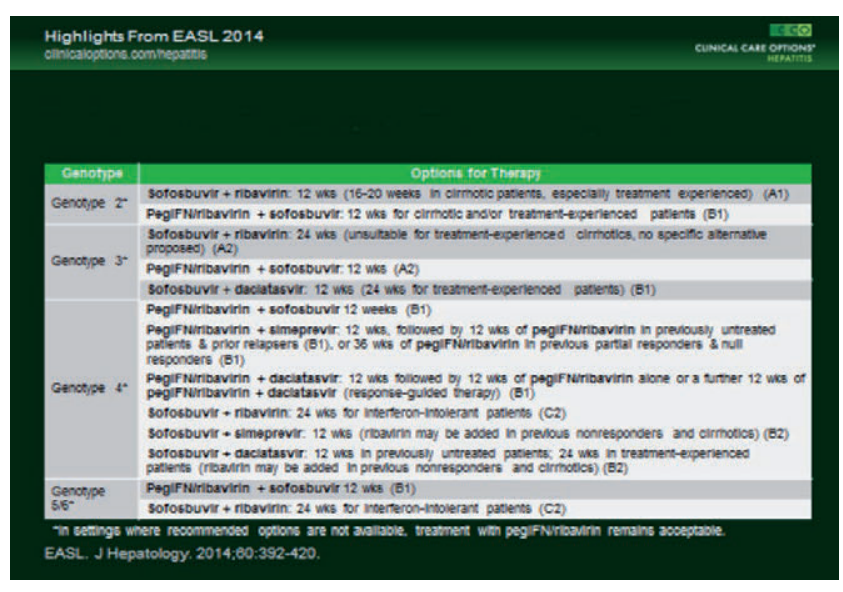

Figure 15. EASL HCV guidelines 2014: Genotype 2-6.

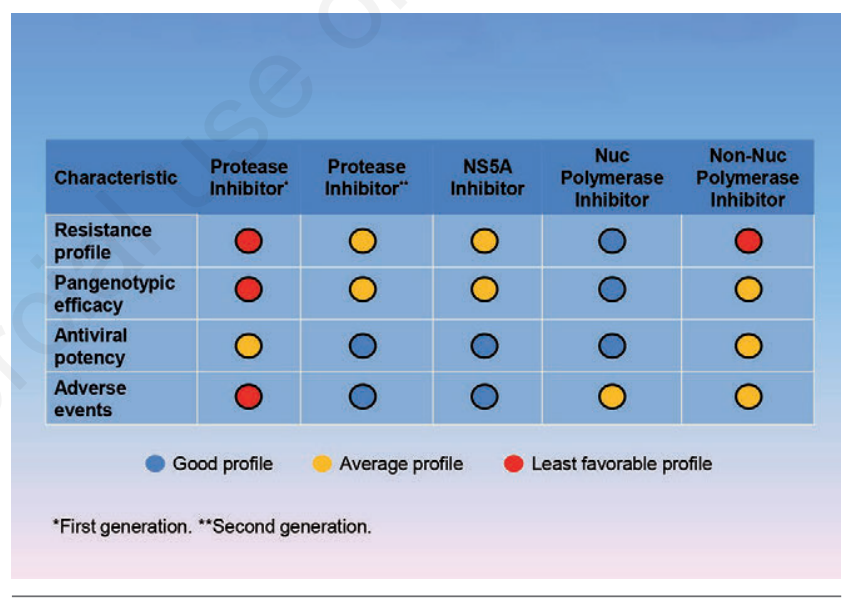

Figure 16. Not all direct-acting antivirals are created equals.

Further treatment options with new molecules are under evaluation, like Miravirsen, a locked nucleic acid-modified DNA phosphorothioate antisense oligonucleotide that sequesters mature miR-122 in a highly stable heteroduplex, thereby inhibiting its function. The stability and propagation of hepatitis $\mathrm{C}$ virus (HCV) is dependent on this functional interaction between the HCV genome and liver-expressed microRNA122 (miR-122). ${ }^{65}$

An important and probably critical issue for the new treatments of $\mathrm{HCV}$ is the high cost that is preventing enthusiasm for their future global application.

In conclusion, talking about HCV treatment today equals to talking about total cure of the patient, with treatments of very high SVR rates, shorter if not shortest duration, ${ }^{66}$ minimal risk for resistance, pangenotypic and practically with no serious adverse events, no fibrosis or previous treatment status limitations, but also with a very high cost. Hope for HCV is now somewhat like living already in the very next day of a world free of hepatitis $\mathrm{C}$. 


\section{References}

1. World Health Organization. Hepatitis B. Fact sheet $\mathrm{N}^{\circ} 204$. Updated July 2014.

2. Conjeevaram HS, Lok AS. Management of chronic hepatitis B. J Hepatol 2003;38 suppl 1:s90-103.

3. Philip Y. Wong, Victor Xia, et al. Clinical Presentation of Hepatocellular Carcinoma (HCC) in Asian-Americans Versus NonAsian-Americans, J Immigr Minor Health. Oct 2011; 13(5): 842-848.

4. World Health Organization. Cancer, Fact sheet $\mathrm{N}^{\circ} 297$, Updated November 2014.

5. Bosch FX, Ribes J, Cléries R, Díaz M. Epidemiology of hepatocellular carcinoma. Clin Liver Dis 2005;9:191-211.

6. Brian J. McMahon, Wallace L. M. Alward, et al. Acute Hepatitis B Virus Infection: Relation of Age to the Clinical Expression of Disease and Subsequent Development of the Carrier State J Infect Dis. (1985) 151 (4): 599-603.

7. Wasley A, Grytdal S, Gallagher K, Centers for Disease Control and Prevention (CDC). Surveillance for acuteviral hepatitis - United States, 2006. MMWR Surveill Summ 2008;57:1-24.

8. Chang MH, et al. Universal hepatitis B vaccination in Taiwan and the incidence of hepatocellular carcinoma in children. Taiwan Childhood Hepatoma Study Group. N Engl J Med 1997;336:1855-9.

9. Fattovich G, Giustina G, Schalm SW, et al. Occurrence of hepatocellular carcinoma and decompensation in western European patients with cirrhosis type B. The EUROHEP Study Group on Hepatitis B Virus and Cirrhosis. Hepatology 1995;21:77-82.

10. Torresi J, Locarnini S. Antiviral chemotherapy for the treatment of hepatitis B virus infections. Gastroenterology 2000;118:S83-103.

11. Seaberg EC, Belle SH, Beringer KC, et al. Liver transplantation in the United States from 1987-1998: updated results from the PittUNOS Liver Transplant Registry. Clin Transpl 1998:17-37.

12. Lok AS, McMahon BJ. Chronic hepatitis B: update 2009. Hepatology 2009;50:661-2.

13. Keeffe EB, Dieterich DT, Han SH, et al. A treatment algorithm for the management of chronic hepatitis $B$ virus infection in the United States: 2008 update. Clin Gastroenterol Hepatol 2008;6: 1315-41.

14. Iloeje UH, Yang HI, Su J, et al. Predicting cirrhosis risk based on the level of circulating hepatitis B viral load. Gastroenterology 2006;130:678-86.

15. Chen CJ, Yang HI, Su J, et al. Risk of hepatocellular carcinoma across a biological gradient of serum hepatitis B virus DNA level. JAMA 2006;295:65-73.

16. Scaglione SJ, Lok AS. Effectiveness of hepatitis B treatment in clinical practice. Gastroenterology 2012;142:1360-1368.e1.

17. Marcellin P, Lau GK, Bonino F, et al. Peginterferon alfa-2a alone, lamivudine alone, and the two in combination in patients with HBeAg-negative chronic hepatitis B. N Engl J Med 2004;351: 1206-17.

18. Lau GK, Piratvisuth T, Luo KX, et al. Peginterferon Alfa-2a, lamivudine, and the combination for HBeAg-positive chronic hepatitis B. N Engl J Med 2005;352:2682-95.

19. Buster EH, Flink HJ, Cakaloglu Y, et al. Sustained HBeAg and HBsAg loss after long-term follow-up of HBeAg-positive patients treated with peginterferon alpha-2b. Gastroenterology 2008;135:459-67.

20. Marcellin P, Bonino F, Lau GK, et al. Sustained response of hepatitis $\mathrm{B}$ e antigen-negative patients 3 years after treatment with peginterferon alpha-2a. Gastroenterology 2009;136:2169-2179.e1-4.

21. Dusheiko G. Treatment of HBeAg positive chronic hepatitis B: interferon or nucleoside analogues. Liver Int 2013;33 Suppl 1:137-50.

22. Lampertico P, Viganò M, Colombo M. Why do I treat HBeAg-nega- tive chronic hepatitis B patients with pegylated interferon? Liver Int 2013;33 Suppl 1:157-63.

23. Tujios SR, Lee WM. Update in the management of chronic hepatitis B. Curr Opin Gastroenterol 2013;29:250-6.

24. Van Bömmel F, Berg T. Treatment of HBV related cirrhosis. Liver Int 2013;33 Suppl 1:176-81.

25. Piratvisuth T. Optimal management of $\mathrm{HBV}$ infection during pregnancy. Liver Int 2013;33 Suppl 1:188-94.

26. Lange CM, Bojunga J, Hofmann WP, et al. Severe lactic acidosis during treatment of chronic hepatitis B with entecavir in patients with impaired liver function. Hepatology 2009;50:2001-6.

27. Liaw YF, Gane E, Leung N, et al. 2-Year GLOBE trial results: telbivudine Is superior to lamivudine in patients with chronic hepatitis B. Gastroenterology 2009;136:486-95.

28. Marcellin P, Chang TT, Lim SG, et al. Long-term efficacy and safety of adefovir dipivoxil for the treatment of hepatitis B e antigen-positive chronic hepatitis B. Hepatology 2008;48:750-8.

29. Marcellin P, Gane E, Buti M, et al. Regression of cirrhosis during treatment with tenofovir disoproxil fumarate for chronic hepatitis B: a 5-year open-label follow-up study. Lancet 2013;381:468-75.

30. Marcellin P, Bonino F, Lau GK, et al. Sustained response of hepatitis $\mathrm{B}$ e antigen-negative patients 3 years after treatment with peginterferon alpha-2a. Gastroenterology 2009;136:2169-2179.e1-4.

31. Sherman M, Yurdaydin C, Sollano J, et al. Entecavir for treatment of lamivudine-refractory, HBeAg-positive chronic hepatitis B. Gastroenterology 2006;130:2039-49.

32. Tenney DJ, Rose RE, Baldick CJ, et al. Long-term monitoring shows hepatitis $\mathrm{B}$ virus resistance to entecavir in nucleosidenaive patients is rare through 5 years of therapy. Hepatology 2009;49:1503-14.

33. Petersen J, Buti M. Considerations for the long-term treatment of chronic hepatitis B with nucleos(t)ide analogs. Expert Rev Gastroenterol Hepatol 2012;6:683-93.

34. Zoulim F, Locarnini S. Optimal management of chronic hepatitis B patients with treatment failure and antiviral drug resistance. Liver Int 2013;33 Suppl 1:116-24.

35. Jindal A, Kumar M, Sarin SK. Management of acute hepatitis B and reactivation of hepatitis B. Liver Int 2013;33 Suppl 1:164-75.

36. Zoulim F. Antiviral therapy of chronic hepatitis B: can we clear the virus and prevent drug resistance? Antivir Chem Chemother 2004;15:299-305.

37. Yeo W, Chan HL. Hepatitis B virus reactivation associated with anti-neoplastic therapy. J Gastroenterol Hepatol 2013;28:31-7.

38. Lee YH, Bae SC, Song GG. Hepatitis B virus (HBV) reactivation in rheumatic patients with hepatitis core antigen (HBV occult carriers) undergoing anti-tumor necrosis factor therapy. Clin Exp Rheumatol 2013;31:118-21.

39. Pol S. Management of HBV in immunocompromised patients. Liver Int 2013;33 Suppl 1:182-7.

40. Alberti A, Chemello L, Benvegnù L. Natural history of hepatitis C. J Hepatol 1999;31 Suppl 1:17-24.

41. Vanwolleghem T, Meuleman P, Libbrecht L, et al. Ultra-rapid cardiotoxicity of the hepatitis $\mathrm{C}$ virus protease inhibitor BILN 2061 in the urokinase-type plasminogen activator mouse. Gastroenterology 2007;133:1144-55.

42. Gane EJ, Roberts SK, Stedman CA, et al. Oral combination therapy with a nucleoside polymerase inhibitor (RG7128) and danoprevir for chronic hepatitis C genotype 1 infection (INFORM-1): a randomised, double-blind, placebo-controlled, dose-escalation trial. Lancet 2010; 376:1467-75.

43. Manns MP, Foster GR, Rockstroh JK, et al. The way forward in HCV treatment-finding the right path. Nat Rev Drug Discov 2007; 6:991-1000.

44. Bacon BR, Gordon Sc, Lawitz E, et al. Boceprevir for previously 
treated chronic HCV genotype 1 infection. N Engl J Med 2011;364:1207-17.

45. Zeuzem S, Andreone P, Pol S, et al. Telaprevir for retreatment of HCV infection. N Engl J Med 2011;364:2417-28.

46. European Association for Study of Liver. EASL Clinical Practice Guidelines: management of hepatitis $\mathrm{C}$ virus infection. J Hepatol 2014;60:392-420.

47. Lawitz E, Mangia A, Wyles D, et al. Sofosbuvir for previously untreated chronic hepatitis C infection. N Engl J Med 2013;368:1878-87.

48. Afdhal N, Zeuzem S, Kwo P, et al. Ledipasvir and sofosbuvir for untreated HCV genotype 1 infection. N Engl J Med 2014;370:1889-98.

49. Kowdley KV, Gordon SC, Reddy KR, et al. Ledipasvir and sofosbuvir for 8 or 12 weeks for chronic HCV without cirrhosis. N Engl J Med 2014;370:1879-88.

50. Poordad F, Hezode C, Trinh R, et al. ABT-450/r-ombitasvir and dasabuvir with ribavirin for hepatitis $\mathrm{C}$ with cirrhosis. $\mathrm{N}$ Engl $\mathrm{J}$ Med 2014;370:1973-82.

51. Kwo P, et al. 0114 RESULTS OF THE PHASE 2 STUDY M12-999: INTERFERON-FREE REGIMEN OF ABT-450/R/ABT-267 + ABT-333 + RIBAVIRIN IN LIVER TRANSPLANT RECIPIENTS WITH RECURRENT HCV GENOTYPE 1 INFECTION, Hepatology 2014: Volume 60, Issue 1, Supplement, Page S47.

52. Afdhal N, Zeuzem S, Kwo P, et al. Ledipasvir and sofosbuvir for untreated HCV genotype 1 infection. N Engl J Med 2014;370:1889-98.

53. Sulkowski MS, Gardiner DF, Rodriguez-Torres M, et al. Daclatasvir plus sofosbuvir for previously treated or untreated chronic HCV infection. N Engl J Med 2014;370:211-21.

54. Poordad F, Lawitz E, Kowdley KV, et al. Exploratory study of oral combination antiviral therapy for hepatitis C. N Engl J Med 2013;368:45-53.

55. Zeuzem S, Soriano V, Asselah T, et al. Faldaprevir and deleobuvir for HCV genotype 1 infection N Engl J Med 2013;369:630-9.
56. Lok AS, Gardiner DF, Lawitz E, et al. Preliminary study of two antiviral agents for hepatitis C genotype 1. N Engl J Med 2012;366:216-24.

57. Jacobson IM, Gordon SC, Kowdley KV, et al. Sofosbuvir for hepatitis $\mathrm{C}$ genotype 2 or 3 in patients without treatment options. N Engl J Med 2013;368:1867-77.

58. Feld JJ, Kowdley KV, Coakley KV, et al. Treatment of HCV with ABT450/r-ombitasvir and dasabuvir with ribavirin. N Engl J Med 2014;370:1594-603.

59. Gane EJ, Stedman CA, Hyland RH, et al. Nucleotide polymerase inhibitor sofosbuvir plus ribavirin for hepatitis C. N Engl J Med 2013;368:34-44.

60. Zeuzem S, Dusheiko GM, Salupere R, et al. Sofosbuvir + ribavirin for 12 or 24 weeks for patients with HCV genotype 2 or 3 : the VALENCE trial, Hepatology 2013;58(4, suppl):733A. 2013;58(4,):733A.

61. Jacobson IM, Gordon SC, Kowdley KV, et al. Sofosbuvir for hepatitis $\mathrm{C}$ genotype 2 or 3 in patients without treatment options. N Engl J Med 2013;368:1867-77.

62. Kieffer TL, George S. Resistance to hepatitis C virus protease inhibitors. Curr Opin Virol 2014;8C:16-21.

63. Paolucci S, Fiorina L, Mariani B, et al. Naturally occurring resistance mutations to inhibitors of HCV NS5A region and NS5B polymerase in DAA treatment-naïve patients. Virol J 2013;10:355.

64. Lawitz E, Poordad FF, Pang PS, et al. Once Daily Sofosbuvir/ledipasvir fixed dose combination with or without ribavirin resulted in $>95 \%$ sustained virologic response in patients with HCV genotype 1, including patients with cirrhosis: the LON ESTAR study[AASLD Abstract 215] Hepatology 2013;58:4-315A.

65. Janssen HL, Reesink HW, Lawitz EJ, et al. Treatment of HCV infection by targeting microRNA. N Engl J Med 2013;368:1685-94.

66. Zeuzem S, Dusheiko GM, Salupere R, et al. Sofosbuvir and ribavirin in HCV genotypes 2 and 3. N Engl J Med 2014;370:1993-2001. 